\title{
Transforming growth factor $B$ signaling inhibitor, SB-431542, induces maturation of dendritic cells and enhances anti-tumor activity
}

\author{
HIROAKI TANAKA, OSAMU SHINTO, MASAKAZU YASHIRO, SADAAKI YAMAZOE, \\ TAKEHIKO IWAUCHI, KAZUYA MUGURUMA, NAOSHI KUBO, \\ MASAICHI OHIRA and KOSEI HIRAKAWA
}

Department of Surgical Oncology, Osaka City University Graduate School of Medicine, Osaka, Japan

Received July 10, 2010; Accepted September 2, 2010

DOI: $10.3892 /$ or_00001028

\begin{abstract}
The transforming growth factor $\beta$ (TGFß) stimulates tumor progression and metastasis. Secretion of TGFß by tumor cells also suppresses an antitumor immune response in which dendritic cells (DCs) play an important role to activate cytotoxic T lymphocytes (CTLs). Herein we report that the small molecule TGFß signaling inhibitor SB-431542, induces DC maturation in vitro and triggers antitumor activity in vivo. We added SB-431542 to cultures of murine bone-marrow derived DCs (BM-DCs) derived from BALB/c mice and human DCs generated from peripheral monocytes (human DCs) at different concentrations in triplicates and examined expression of co-stimulatory molecules by FACS and production of Interleukin-12 (IL-12) by ELISA. SB induced phenotypic maturation of BM-DCs and human DCs and improved their abilities to produce IL-12 in a dose-dependent manner. SB-431542 also augmented capacity of murine and human DCs to activate naïve $\mathrm{T}$ cells in allogeneic mixed lymphocyte reaction. Interestingly, SB-431542 augmented the capacity of BM-DCs and human DCs to incorporate FITC-conjugated dextran. Intraperitoneal administration of SB-431542 intiated 3 and 7 days after the implantation of colon-26 cancer cells into the peritoneal cavity of BALB/c mice significantly induced CTL activity against colon-26. We incubated human DCs with SB-431542 and cell lysate of scirrhous gastric cancer cell line OCUM-8, and then examined CTL activities against OCUM-8. CD8 T cells activated by human DCs treated with SB-431542 showed modest augmentation CTL activity against cancer cells. Furthermore, pretreatment of human DCs with SB-431542 upregulated cytotoxic activity against K562 cells, suggesting
\end{abstract}

Correspondence to: Dr Hiroaki Tanaka, Department of Surgical Oncology, Osaka City University Graduate School of Medicine, 1-4-3, Asahimachi, Abeno-ku, Osaka 545-8585, Japan

E-mail: hiroakitan@med.osaka-cu.ac.jp

Key words: dendritic cell, TGFß inhibitor, anti-tumor immunity
SB should have potential to activate DCs to natural killer cells. In conclusion, TGFß receptor I kinase inhibitor such as SB-431542 might induce anti-tumor immune response in immuno-tolerant patients associated with TGFß activity.

\section{Introduction}

Dendritic cells (DCs) are professional antigen-presenting cells with an ability to trigger primary adoptive immune responses to cancer cells (1). DCs have been used in cancer immunotherapeutic approaches such as adoptive transfer of ex vivo expanded DC preparation after loading with tumor antigens (i.e., DC vaccines), intratumor administration of DC-attracting chemokines, and use of DC-stimulatory agents as adjuvants (2-5). Although mature DCs possess functional properties required for presenting tumor-associated antigens to $\mathrm{T}$ cells, several mechanisms have been reported by which tumor cells escape from immune surveillance (6). For example, cancer cells suppress the development and maturation of DCs by elaborating various immunosuppressive factors, such as transforming growth factor $\beta$ (TGFß), vascular endothelial growth factor, and interleukin (IL)-10 $(7,8)$.

Generally, TGFß is apleiotropic cytokine that exerts inhibitory effects on mesenchymal cells, including hematopoietic progenitor cells (9). This inhibitory potential of TGFß is central to the tumor-suppressive mechanism (10). However, as tumors develop, they often overexpress TGFß, which impacts on the biology of tumor cells and creates a tumormicroenvironment that is associated with metastasis (11). At present, several studies have focused on the therapeutic potential of antagonizing the TGFß pathway against cancer $(12,13)$. The most advanced TGFß signaling antagonist in clinical development is large-molecule including monoclonal antibodies (14-16). During this decade, many small molecules to inhibit TGFß type I receptor have been developed. Seven type I receptors have been identified to date (activin receptor kinese, ALKs) $(17,18)$. SB-431542 acts as a competitive ATP binding site kinase inhibitor and is a selective inhibitor for ALK4, -5, and -7 (19). In the present study, we examined the impact of TGFß receptor inhibitor, SB-431542, on DC maturation in vitro and antitumor response in the immunologically tolerant status associated with TGFß activity. 


\section{Materials and methods}

Animals. Mice were purchased from Japan Clair (Tokyo, Japan). The animal use Committee of the University of Osaka City University approved all protocols in compliance with the Guide for the Care and Use of Laboratory Animals.

Cell lines and chemical. A human scirrhous gastric cancer cell line, OCUM-8 and a murine colorectal adenocarcinoma cell line, colon-26 were maintained in RPMI-1640 supplemented with $10 \%$ heat-inactivated fetal bovine serum (FBS) (20). SB-431542, a TGFßR inhibitor was synthesized as described previously and was purchased from Sigma Aldrich (USA).

Western blot analysis. The inhibitory effect on Smad2 phosphorylation of SB-431542 in DCs was examined as follows. BM-DCs $\left(1 \times 10^{6}\right)$ were incubated in serum-free RPMI with TGF3 (0 or $10 \mathrm{ng} / \mathrm{ml})$ and SB-431542 $(0-10 \mu \mathrm{M})$ for $60 \mathrm{~min}$. Total cell lysate $(30 \mu \mathrm{g})$ were subjected to SDS-PAGE, and the protein bands were transferred to a polyvinylidene difluoride membrane (Amersham, Aylesbury, UK). The membrane was placed in the TBS-T solution containing the anti-Phospho-Smad2 (Cell Signaling Technology, Danvers, CO, Ser 465/467; 1:1000), Smad2/3 (Cell Signaling Technology, 1:1000) antibody, and allowed to react at $4^{\circ} \mathrm{C}$ overnight. The bands were detected using an enhanced chemiluminescence system (Amersham). An immunoblot analysis was performed twice.

Generation of murine bone marrow derived DCs (BM-DCs) and human DCs. Mouse bone-marrow derived DCs were prepared as described before $(5,21,22)$. Briefly, mouse DCs were generated from bone marrows of BALB/c mice (8-12 weeks old female) using RPMI-1640 medium with $10 \%$ fetal calf serum (FCS), $10 \mathrm{ng} / \mathrm{ml}$ murine recombinant granurocytemacrophage colony-stimulating factor (GM-CSF). On day 2 and 4 of culture, floating cells were gently removed and fresh medium with cytokine was replaced. Monocyte-derived DCs were generated from peripheral mononuclear lymphocytes (PBMCs) using standard method as described before (23). Briefly, PBMCs were plated in $100 \times 20-\mathrm{mm}$ tissue culture plates at the density of $2.0 \times 10^{7}$ cells per dish in $5 \mathrm{ml}$ of RPMI-1640 medium without serum. Non-adherent cells were removed carefully. The remaining cells were cultured for 6 days in RPMI-1640 with $2 \%$ heat-inactivated autologous human serum, $10 \mathrm{ng} / \mathrm{ml}$ of recombinant human GM-CSF and interleukin-4 (Peprotech EC Ltd., London, UK).

Effects of SB-431542 on murine BM-DCs and human DCs. DCs were incubated in 96-well plates $\left(5 \times 10^{4}\right.$ cells/200 $\mu \mathrm{l} /$ well $)$ with SB-431542 or vehicle alone and LPS in the presence of LPS at different concentrations in triplicates, and then examined for expression of co-stimulatory molecules using FACSCalibur. After $24 \mathrm{~h}$ of incubation, the cells were examined for surface expression of CD86 or CD83 within the $\mathrm{CD} 11 \mathrm{c}^{+}$populations, and the supernatants were tested for cytokine production by enzyme-linked immunosorbent assay (ELISA). Following $24 \mathrm{~h}$ of incubation with a test drug, BM-DCs were incubated for $10 \mathrm{~min}$ with $5 \mathrm{mg} / \mathrm{ml}$ of fluorescein isothiocyanate (FITC)-conjugated dextran (DX)

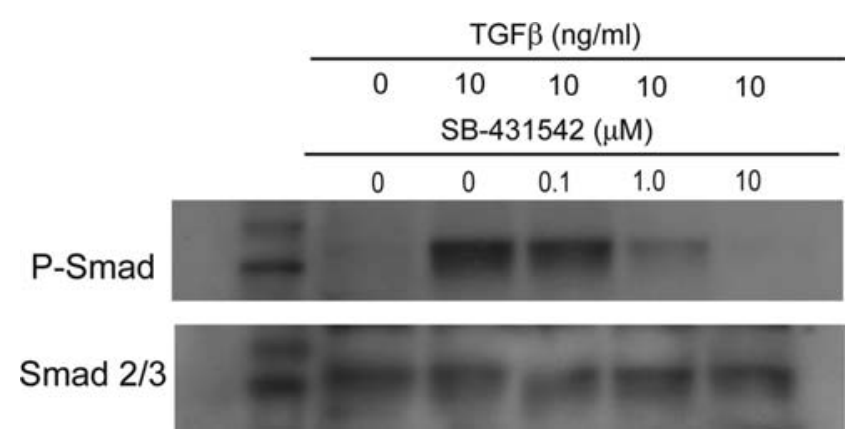

Figure 1. Effect of SB-431542 on Smad phosphorylation of DCs. BM-DCs were treated with TGFß $(10 \mathrm{ng} / \mathrm{ml})$ for $1 \mathrm{~h}$ in the presence or absence of SB-431542 (0.1-10 $\mu \mathrm{M})$, which was added $30 \mathrm{~min}$ before ligand stimulation. Phosphorylation of Smad protein was examined by immunoblotting using anti-phospho-Smad2 (upper panel) and anti-Smad2/3 (lower panel).

(70,000 Dalton molecular weight, Sigma) at $4^{\circ} \mathrm{C}$ or $37^{\circ} \mathrm{C}$, washed extensively, and then examined for FITC signals by CD $11 \mathrm{c}^{+}$cells. After drug pretreatment, BM-DC preparations (derived from BALB/c mice) were washed 3 times and then co-cultured in 96 round-bottom well plates at 4 different cell densities $\left(0.3-10 \times 10^{3}\right.$ cells/well $)$ with splenic $\mathrm{T}$ cells purified from C57BL/6 mice $\left(5 \times 10^{4}\right.$ cells/well). The magnitude of $\mathrm{T}$ cell proliferation was assessed by ${ }^{3} \mathrm{H}$-thymidine uptake on day 4. Human DC cultures derived from PBMCs were examined for surface phenotype within the $\mathrm{CD} 11 \mathrm{c}^{+}$population and cytokine production by ELISA as well as for allogeneic mixed lymphocyte reaction.

CTL response and assays. $\mathrm{BALB} / \mathrm{c}$ mice received intraperitoneal (i.p.) injections of colon-26 tumor cells. Three days after tumor cell inoculation, SB-431542 (1 $\mu \mathrm{M}$ solution, $100 \mu \mathrm{l} /$ animal) or vehicle alone was directly injected into peritoneal cavity. CTL activities were measured by a standard $4 \mathrm{~h}{ }^{51} \mathrm{Cr}$ release assay after culturing spleen cells with $\gamma$-irradiated tumor cells for five days in the absence of added growth factors. All animal experiments were conducted according to the guideline of animal care at Osaka City University. In vitro experiments, cell lysate of HLA-A*2402 positive gastric cancer cell line, OCUM-8, was incubated with human DC cultures for $4 \mathrm{~h}$. After washing extensively, PBMCs obtained from the same volunteer as DCs were incubated for 7 days and measured CTL activity by ${ }^{51} \mathrm{Cr}$ release assay. NK activity was tested using ${ }^{51} \mathrm{Cr}$ release assay against K562.

Statistical analysis. All in vitro measurements were made in triplicate samples and each test drug was compared to vehicle alone control by a Two-tailed Student's t-test. Each in vitro test was repeated at least 3 times to assess reproducibility. Differences with $\mathrm{P}<0.05$ were considered to be statistically significant.

\section{Results}

Impacts of SB-431542 on expression of co-stimulatory molecules and production of IL-12 by murine and human DCs. Inhibitory effect of SB-431542 on TGFß signaling was evaluated in BM-DCs in vitro. BM-DCs express a basal level 

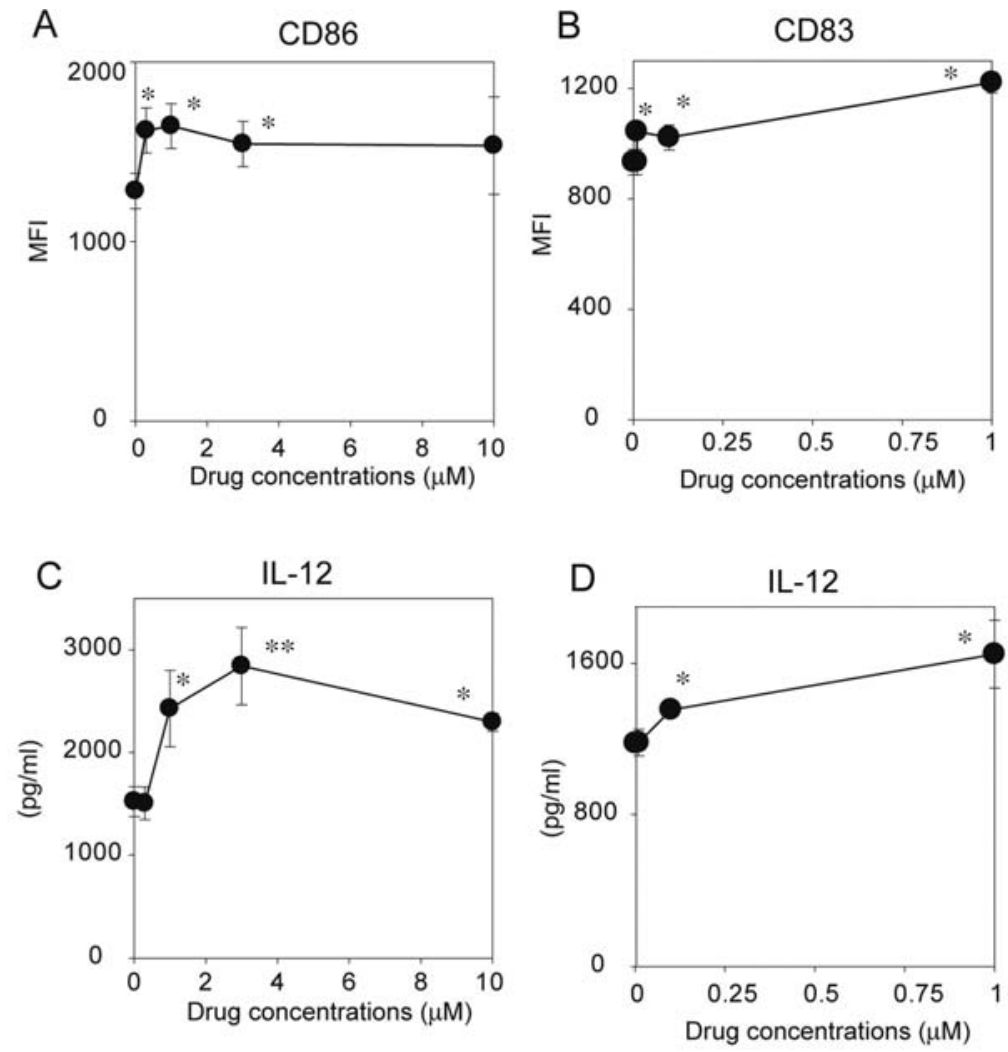

E

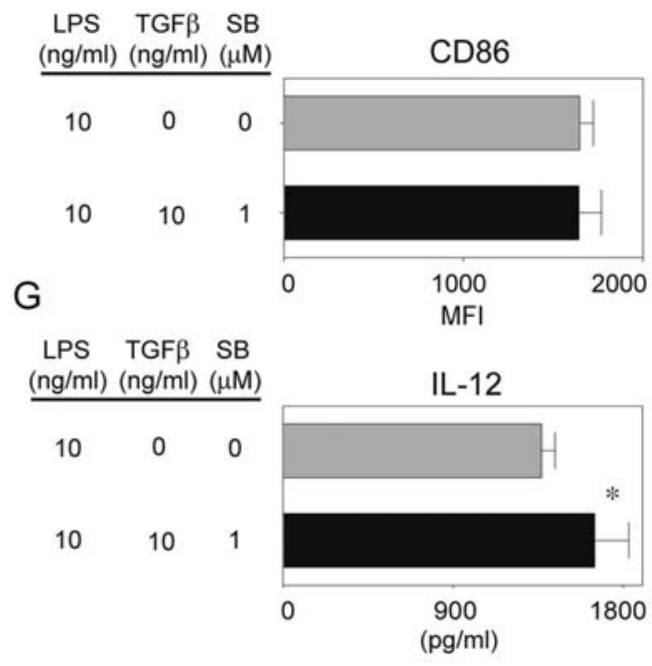

$\mathrm{F}$
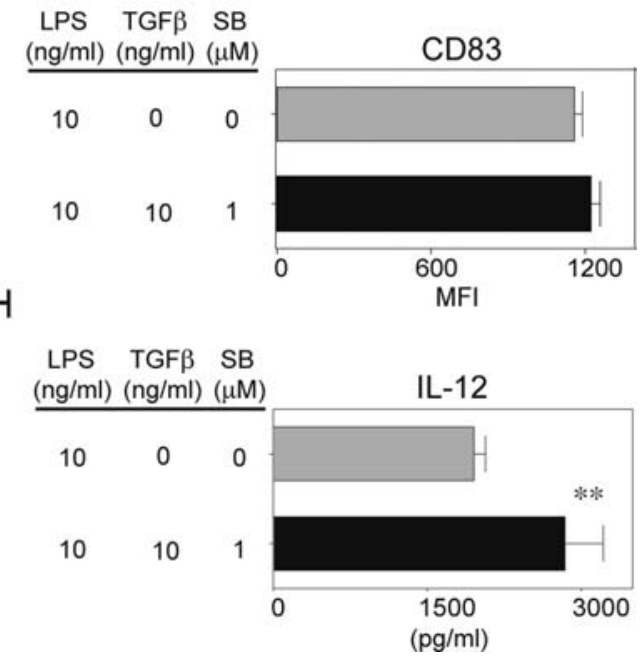

Figure 2. Effects of SB-431542 on BM-DCs and human DCs. (A and E) Following $24 \mathrm{~h}$ of incubation with SB-431542 (0.1-10 $\mu$ M) in the presence or absence of TGFß $(10 \mathrm{ng} / \mathrm{ml})$, the supernatants of BM-DC cultures propagated from BALB/c mice were examined for their surface expression of CD86 (mean fluorescence intensity, MFI) within CD11 $\mathrm{c}^{+}$population (mean $\pm \mathrm{SD}, \mathrm{n}=3$ ). (B and F) Human DCs generated from peripheral blood monocytes (PBMCs) of healthy volunteers were incubated with SB-431542 (0.01-1 $\mu \mathrm{M})$ in the presence of TGFß $(10 \mathrm{ng} / \mathrm{ml})$. The human DCs were examined for their CD83 expression within $\mathrm{CD} 11 \mathrm{c}^{+}$population (mean $\left.\pm \mathrm{SD}, \mathrm{n}=3\right)$. $(\mathrm{C}$ and $\mathrm{G})$ The supernatants of BM-DC cultures propagated from BALB/c mice were examined for production of IL-12p70 (mean $\pm \mathrm{SD}, \mathrm{n}=3$ ). ( $\mathrm{D}$ and $\mathrm{H}$ ) The supernatants of human DC cultures were examined for production of IL-12p40 (mean $\pm \mathrm{SD}$, $\mathrm{n}=3$ ). Statistically significant differences compared to vehicle-treated control samples are indicated with asterisks $\left({ }^{*} \mathrm{P}<0.05\right.$, $\left.{ }^{* *} \mathrm{P}<0.01\right)$. Each experiment was repeated at least three times to assess reproducibility.

of phosphorylated Smad2 by incubation with TGFß (Fig. 1). SB-431542 prevented the TGFß-dependent elevation of phosphorylated Smad2 dose-dependently. At the concentraton of $10 \mu \mathrm{M}, \mathrm{SB}-431542$ showed complete blocking of Smad phosphorylation (Fig. 1). We next examined for surface expression of CD86 which is well known as a maturation marker of BM-DCs and CD83 of human monocyte derived DCs (human DCs), within the CD11 $\mathrm{c}^{+}$ populations. To test this, we treated mouse bone BM-DCs or human DCs with SB-431542 at different concentrations for $24 \mathrm{~h}$ in the presence or absense of recombinant TGFß. Lipopolysaccharide (LPS) was used to mature DCs at a concentration of $10 \mathrm{ng} / \mathrm{ml}$. As shown in Fig. 2A, SB-431542 significantly elevated the CD86 expression of BM-DCs 

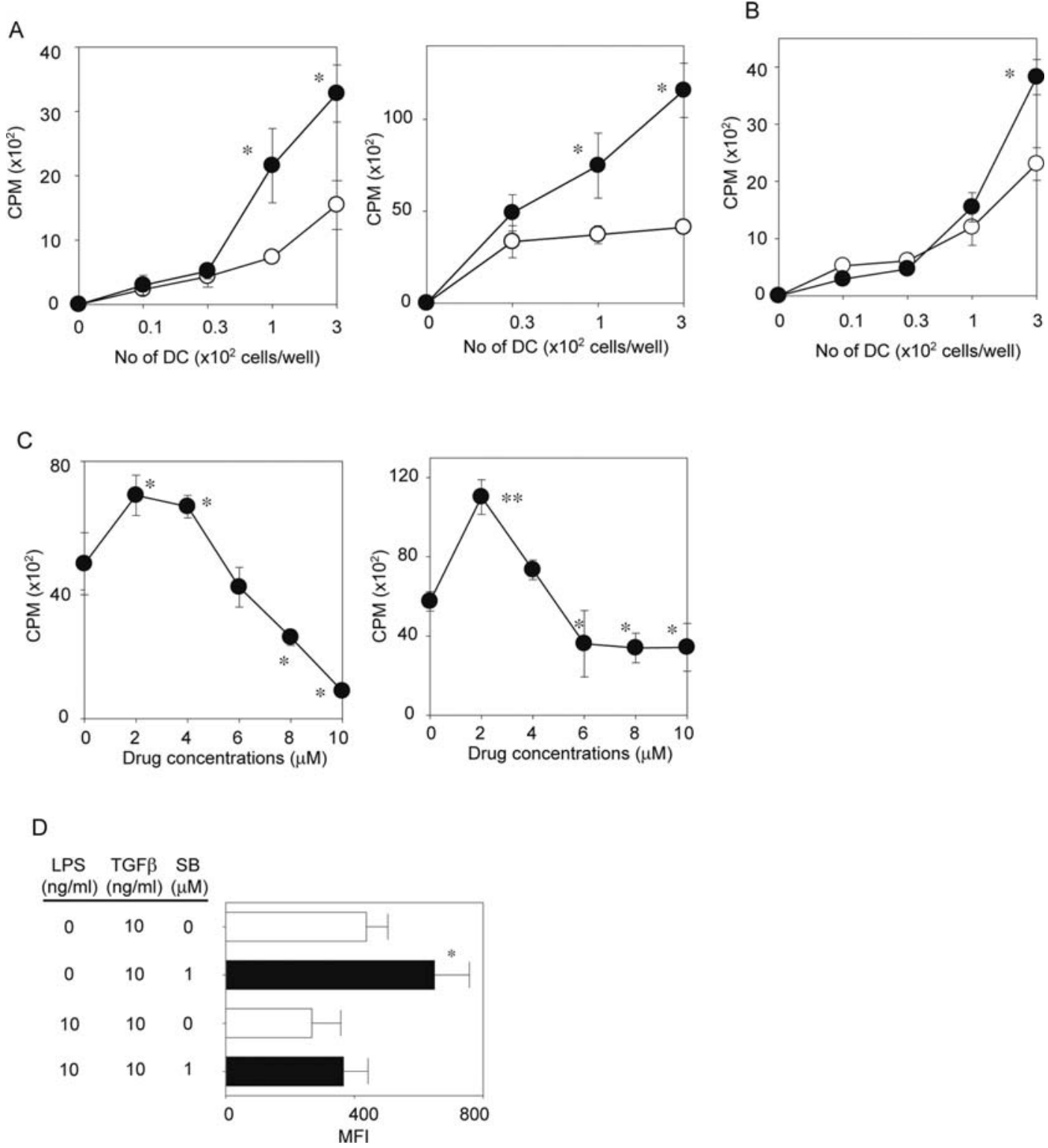

Figure 3. Impact of SB-431542 on function of DCs. (A) Following $24 \mathrm{~h}$ of pretreatment with $1 \mu \mathrm{M}$ SB-431542 (closed circles) or vehicle alone (open circles), BM-DCs (left panel) propagated from BALB/c mice and human DCs (right panel) generated from PBMCs were added at the indicated cell numbers to microcultures of CD8 T cells $\left(5 \times 10^{4}\right.$ cells/well) purified from C57BL/6 mice (left panel) and allogeneic PBMCs (right panel). Data shown are mean \pm SD $(\mathrm{n}=3)$ of $\left[{ }^{3} \mathrm{H}\right]$-thymidine uptake harvested on day 3. (B) BM-DCs pretreated with LPS and SB-431542 (closed circles) or LPS and vehicle (open circles) were incubated with allogeneic CD8 T cells. Data shown are the mean $\pm \mathrm{SD}(\mathrm{n}=3)$ of $\left[{ }^{3} \mathrm{H}\right]$-thymidine uptake harvested on day 3. (C) Cells $\left(1 \times 10^{2}\right)$ of BM-DCs $($ left

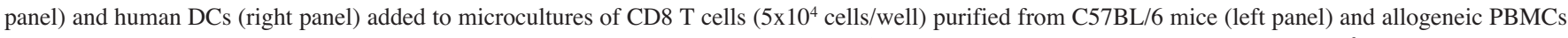
(right panel) in the presence of TGFB $(10 \mathrm{ng} / \mathrm{ml})$ and the indicated dose of SB-431542. Data shown are the mean $\pm \mathrm{SD}(\mathrm{n}=3)$ of $\left[{ }^{3} \mathrm{H}\right]$-thymidine uptake harvested on day 3. (D) BM-DCs propagated from BALB/c mice were incubated for $24 \mathrm{~h}$ with $1 \mathrm{mM} \mathrm{SB}-431542$ (filled histograms) or vehicle alone (open histograms) and then incubated for $10 \mathrm{~min}$ with FITC-DX at 4 or $37^{\circ} \mathrm{C}$. Data shown are the FITC fluorescent signals within CD $11 \mathrm{c}^{+}$populations. Statistically significant differences compared to the vehicle-treated DCs are indicated with asterisks $\left({ }^{*} \mathrm{P}<0.05 ;{ }^{* *} \mathrm{P}<0.01\right)$.

suppressed by TGFß at concentration range of $0.3-3 \mu \mathrm{M}$. Following $48 \mathrm{~h}$ of incubation, human DCs treated with SB431542 significantly up-regulated expression of CD83 within CD11 $\mathrm{c}^{+}$cells in the presence of TGFß (Fig. 2B). These co-stimulatory molecules improved their expression levels to that of non-immunosuppressive status (Fig. 2E and F). It should be noted that the viabilities of BM-DCs and Mo-DCs remained mostly unchanged after incubation with SB-431542 at tested concentration. Secretion of IL-12p70 by DCs directs the differentiation of naïve Th cells into Th1 lymphocytes. Thereby, we next tested supernatants collected from DC cultures treated with SB-431542 for production of IL-12p70, which is a critical cytokine to induce Th- 1 responses. No IL-12 was detectable in supernatants of cells treated with SB-431542 alone, whereas SB-431542 with LPS treatment dosedependently augmented the production of IL-12 by both DCs in spite of regressive status by TGFß (Fig. 2C and D). Interestingly, this IL-12 production by SB-431542 showed significantly higher levels compared with simple stimulation of LPS in the absence of TGFß (Fig. 2G and H).

Impact of SB-431542 on function of murine and human DCs. A functional hallmark of DC maturation is the acquisition of an elevated capacity to activate naïve T cells. Following $24 \mathrm{~h}$ 
B

A

LPS TGF $\beta$ SB

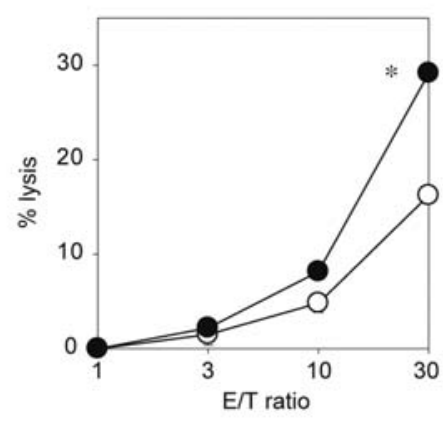

$\underline{(\mathrm{ng} / \mathrm{ml})(\mathrm{ng} / \mathrm{ml})(\mu \mathrm{M})}$

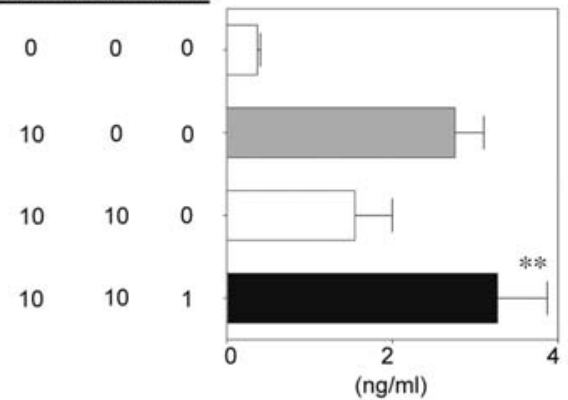

C

D
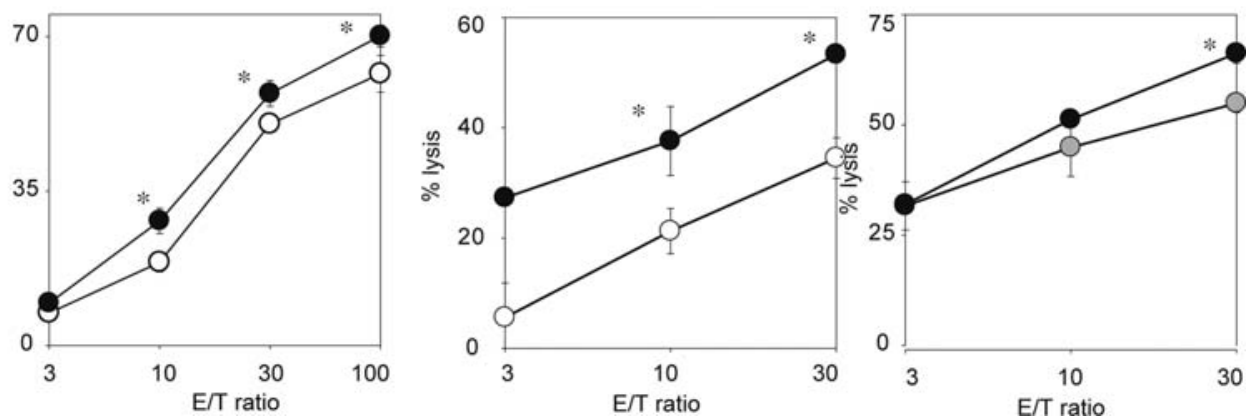

Figure 4. Effect of SB-431542 on cytotoxic activity in vitro and in vivo. (A) Following $24 \mathrm{~h}$ of incubation with $1 \mu \mathrm{M}$ SB-431542 (closed circles) or vehicle alone (open circles) in the presence of TGFß $(10 \mathrm{ng} / \mathrm{ml})$ and LPS $(10 \mathrm{ng} / \mathrm{ml})$, human DC preparations were washed 3 times and then co-cultured in roundbottomed 96-well plates with allogeneic PBMCs. After 48 h, NK activity against K562 was examined using the standard 4-h ${ }^{51} \mathrm{Cr}$ releasing assay. Data shown are the mean $\pm \mathrm{SD}(\mathrm{n}=3)$ of the $\%$ specific lysis measured at the indicated effector/target ratios. (B) The supernatant was examined for IFN $\gamma$ production by ELISA. (C) Cell lysates of OCUM-8, which is a HLA-A*2402 positive gastric cancer cell line, were incubated with human DCs treated with $1 \mu$ M SB-431542 (closed circles) or vehicle alone (open circles) for $4 \mathrm{~h}$. After washing extensively, these DCs were incubated with PBMCs obtained from the same volunteer for 7 days and CTL activities against OCUM- 8 were measured by ${ }^{51} \mathrm{Cr}$ release assay. (D) BALB/c mice bearing CT26 tumor cells received intraperitoneal injections of $1 \times 10^{-4} \mu \mathrm{mol} \mathrm{SB}-431542$ (closed circles, left panel) or vehicle alone (open circles, left panel), SB-431542 with OK-432 (closed circles, right panel) or OK-432 alone (closed circles, right panel) on days 3 and 7 and sacrificed on day 14 to measure CTL activities against CT26 target. Data shown are mean $\pm \mathrm{SD}(\mathrm{n}=3)$ of the $\%$ specific lysis measured at the indicated effector/target ratios. Statistically significant differences compared to vehicle-treated DCs are indicated with asterisks $\left({ }^{*} \mathrm{P}<0.05\right)$

of incubation with SB-431542, DCs were washed intensively and tested for their capacity to activate allogeneic $\mathrm{T}$ cells in the primary mixed leukocyte reactions (MLR). Pretreatment of DCs with SB-431542 at $1 \mu \mathrm{M}$ which we determined as appropriate dose to induce CD86 expression and IL-12 production improved significantly $\mathrm{T}$-cell stimulatory capacity compared with vehicle pretreatment (Fig. 3A). Moreover, T cell proliferation was augmented when BM-DCs were pretreated with both of SB-431542 and LPS compared with LPS alone (Fig. 3B). However, in this allo-MLR system, high dose of SB-431542 $(>5 \mu \mathrm{M})$ strongly reduced $\mathrm{T}$ cell proliferation, suggesting that TGFß is necessary for clonal proliferation of T cells (Fig. 3C). To examine for endocytic capacity, we measured FITC-Dextran uptake by immature DCs with pretreatment of SB-431542 or vehicle alone. In this study, BM-DCs treated with SB-431542 showed modest FIDC-Dextran uptake compared to DCs treated with vehicle alone (Fig. 3D).

Impact of SB-431542 on cytotoxic activity in vitro and in vivo. It has been known that DCs directly trigger natural killer (NK) cell activations, resulting in innate anti-tumor immune response. Thus, we tested their capacity to activate NK cells as an additional functional parameter of DCs using stimulation of allogeneic PBMCs by MLR. NK activities of PBMCs in allo-MLR stimulated with SB-431542-pretreated DCs significantly revealed higher than those of vehicle alone (Fig. 4A). In fact, PBMCs activated by human DCs pretreated with SB-431542 triggered high amount of IFN $\gamma$ (Fig. 4B). Importantly, SB-431542 treatment also augmented elevated level of IFN $\gamma$ compared with that in the absence of TGFß (Fig. 4B). These results indicate that SB-431542 is able to induce NK activity mainly through functional maturation and IL-12 production of human DCs.

A key question was whether SB-431542 would provoke anti-tumor immunity as suggested in the in vitro DC activation. To clarify this, human DCs pretreated with SB431542 were incubated for $8 \mathrm{~h}$ with the cell lysate of scirrhous gastric cancer cell line OCUM-8, which has HLAA*2402, then co-cultured with CD8 $\mathrm{T}$ cells which has the same HLA allele to present tumor antigen by human DCs. Following a 5-day incubation, CD8 T cells react with $\mathrm{Cr}$ labeled OCUM-8 and released $\mathrm{Cr}$ was measured for cytotoxic activity. CD8 T cells activated with human DCs treated with SB showed modest augmentation of cytotoxic activity against cancer cells (Fig. 4C).

Colon 26 colon carcinoma model has been shown to produce substantial amount of TGFß. Using this model, we 
examined whether SB-431542 treatment could trigger antitumor immunity in vivo. Intraperitoneal injection of SB-431542 resulted in triggering CTL activities against colon-26 targets compared with vehicle alone (Fig. 4D). Moreover, the CTL activity against colon-26 cells was more potent when treated with SB combined a ligand for toll-like receptor 4, OK-432, compared with OK-432 alone (Fig. 4D, right panel). Thus, SB431542 is likely to produce antitumor immunological outcomes through alteration of DC function suppressed by TGFß.

\section{Discussion}

In this study, we observed that SB-431542, a small-molecule inhibitor of the TGFß receptor kinase domain, develops DC maturation and induces anti-tumor immunity. SB-431542 promoted phenotypic and functional maturation, including expression of co-stimulatory molecules, production of IL-12, and $\mathrm{T}$ cell proliferation by both of murine BM-DC and human DCs. Moreover, SB-431542 augmented NK cell activity through DC activation and caused significant CTL activity against cancer in vitro and in vivo model. Our results suggested a new concept that small-molecule TGFß RI may achieve immunotherapeutic effect for cancer with regard to overcoming immunotolerant status.

As tumors progress, they often become refractory to TGF 3 mediated anti-tumor mechanism, resulting in formation of tumor growth and metastasis. There are some studies describing that TGFß antagonists may be potent for therapeutic utility preventing metastasis of carcinoma $(24,25)$. For example, recombinant Betaglycan known as TGFß type III receptor antagonist suppressed growth and metastasis of breast cancer in part by inhibiting angiogenesis $(26,27)$. Another important role of TGFß is to maintain tolerance via regulation of the immune system including lymphocyte proliferation, differentiation and survival (9). It has been reported that TGFß-producing cells, such as tumor cells, fail in the development and maturation of DCs as well as stimulation of CTL responses in vitro and in vivo $(28,29)$. Thus, we hypothesized that inhibition of TGFß not only prevents cancer progression but also induces active immunity against cancer in the immuno-suppressive status.

We found SB-431542 to efficiently inhibit phosphorylation of Smad2 by DCs at a concentration of $1 \mu \mathrm{M}$, in agreement with other studies $(30,31)$. SB-431542 has been reported to inhibit TGFß-induced growth of human osteosarcoma cells at a concentration of $0.3 \mu \mathrm{M}(30)$. Complete inhibition of Smad2 phosphorylation was achieved at a concentration of $10 \mu \mathrm{M}$ in this study; however, SB-431542 showed no toxic effect against DCs at the tested dose. Maturation of DCs is characterized by increasing surface expression of costimulatory molecules such as CD83, CD86 and initiating production of Th1 cytokines such as IL-12, triggering the differentiation of naive Th cells into Th1 lymphocytes (32). In the present study, TGFß had an inhibitory effect on DC maturation including downregulation of CD86 or CD83 and secretion of IL-12p70 in both murine and human DCs. These results are consistent with previous studies $(33,34)$.

Importantly, despite suppression by TGFß, SB-431542 significantly improved this co-stimulatory expression and IL-12 production by DCs. Moreover, SB-431542 was capable of triggering more IL-12 production compared to LPS-induced upregulation in the absence of TGFß. This result might be explained by the report that $\mathrm{Smad} 2$ protein is important in the production of IL-12 by DCs (35). For example, toll-like receptor (TLR) ligands such as LPS, which induce huge production of IL-12, have an ability to inhibit Smad2 phosphorylation in human monocyte cells (34). Moreover, in DCs, TGFß inhibits LPS-induced upregulation of NF-кB through activation of Smad proteins, resulting in reduced IL-12 production (36). Based on this evidence, it is likely that the combination of SB-431542 with LPS should be able to augment production of IL-12 through strong inhibition of Smad2 phosphorylation in DCs. Although it has been generally believed that DC maturation is accompanied by a diminished endocytic capacity, our results showed pretreatment with SB-431542 to increase FITC-DX uptake by DCs. This result is supported by the study that BM-DCs stimulated with ligands for TLRs exhibit augumented uptake of FITC-DX (37).

We demonstrated that SB-431542 increased the capacity of DCs to induce the proliferation of naive T cells. In contrast, high doses of SB-431542 significantly reduced proliferation of $\mathrm{T}$ cells, suggesting that SB really can block the role of TGF 3 in the immune system, including the regulation of lymphocyte proliferation, differentiation and survival. Our findings that human DCs pretreated by SB augmented NKdependent cytotoxic activity and IFN $\gamma$ secretion are consistent with other studies that DCs directly activate resting NK cells, resulting in substantial increases in both NK cell cytolytic activity against cancer and IFN $\gamma$ production (38). In addition, PBMCs stimulated with antigen-loaded DCs, which were pretreated by SB in the presence of TGFß improved cancer cell-specific cell lysis, indicating that DCs treated with SB431542 should be able to present tumor associated antigen to CTL and trigger specific CTL activity against cancer. Moreover, we observed that intraperitoneal administration of SB-431542 significantly induces cancer-specific CTL activities in a TGFß-producing animal model. Taken together, these results demonstrate that SB-431542 can induce potent phenotypic and functional maturation of murine and human DCs. Although we can find several studies of the immunological therapeutic effect of TGFß blocking $(39,40)$, this is the first published study in which a small-molecule inhibitor of the TGFß receptor triggers maturation of DCs.

In conclusion, according to immunological effect, smallmolecule inhibitors of the TGFß receptor such as SB-431542 have the potential to broaden the therapeutic ability to inhibit tumor development in the immunosuppressive microenvironment.

\section{Acknowledgements}

This study was supported by Grant-in-Aid Scientific Research (to H.T., Y.M., and K.H.).

\section{References}

1. Steinman RM and Banchereau J: Taking dendritic cells into medicine. Nature 449: 419-426, 2007.

2. O'Neill DW, Adams S and Bhardwaj N: Manipulating dendritic cell biology for the active immunotherapy of cancer. Blood 104: 2235-2246, 2004. 
3. Banchereau J and Palucka AK: Dendritic cells as therapeutic vaccines against cancer. Nat Rev Immunol 5: 296-306, 2005.

4. Melief CJ: Cancer immunotherapy by dendritic cells. Immunity 29: 372-383, 2008.

5. Tanaka $\mathrm{H}$, Matsushima $\mathrm{H}$, Mizumoto $\mathrm{N}$ and Takashima $\mathrm{A}$ : Classification of chemotherapeutic agents based on their differential in vitro effects on dendritic cells. Cancer Res 69: 6978-6986, 2009.

6. Dunn GP, Old LJ and Schreiber RD: The three Es of cancer immunoediting. Annu Rev Immunol 22: 329-360, 2004.

7. Zou W: Immunosuppressive networks in the tumour environment and their therapeutic relevance. Nat Rev Cancer 5: 263-274, 2005.

8. Kim R, Emi M, Tanabe K and Arihiro K: Tumor-driven evolution of immunosuppressive networks during malignant progression. Cancer Res 66: 5527-5536, 2006.

9. Li MO, Wan YY, Sanjabi S, Robertson AK and Flavell RA: Transforming growth factor-beta regulation of immune responses. Annu Rev Immunol 24: 99-146, 2006.

10. Massague J, Blain SW and Lo RS: TGFbeta signaling in growth control, cancer, and heritable disorders. Cell 103: 295-309, 2000 .

11. Arteaga CL: Inhibition of TGFbeta signaling in cancer therapy. Curr Opin Genet Dev 16: 30-37, 2006.

12. Pinkas $\mathrm{J}$ and Teicher BA: TGF-beta in cancer and as a therapeutic target. Biochem Pharmacol 72: 523-529, 2006.

13. Yingling JM, Blanchard KL and Sawyer JS: Development of TGF-beta signalling inhibitors for cancer therapy. Nat Rev Drug Discov 3: 1011-1022, 2004

14. Wong TT, Mead AL and Khaw PT: Prolonged antiscarring effects of ilomastat and MMC after experimental glaucoma filtration surgery. Invest Ophthalmol Vis Sci 46: 2018-2022, 2005

15. Fakhrai H, Dorigo O, Shawler DL, Lin H, Mercola D, Black KL, Royston I and Sobol RE: Eradication of established intracranial rat gliomas by transforming growth factor beta antisense gene therapy. Proc Natl Acad Sci USA 93: 2909-2914, 1996

16. Fujita T, Teramoto K, Ozaki Y, Hanaoka J, Tezuka N, Itoh Y, Asai T, Fujino S, Kontani K and Ogasawara K: Inhibition of transforming growth factor-beta-mediated immunosuppression in tumor-draining lymph nodes augments antitumor responses by various immunologic cell types. Cancer Res 69: 5142-5150, 2009

17. Sawyer JS, Anderson BD, Beight DW, Campbell RM, Jones ML, Herron DK, Lampe JW, McCowan JR, McMillen WT, Mort N, Parsons S, Smith EC, Vieth M, Weir LC, Yan L, Zhang F and Yingling JM: Synthesis and activity of new aryl- and heteroarylsubstituted pyrazole inhibitors of the transforming growth factorbeta type I receptor kinase domain. J Med Chem 46: 3953-3956, 2003

18. Gellibert F, Woolven J, Fouchet MH, Mathews N, Goodland H, Lovegrove V, Laroze A, Nguyen VL, Sautet S, Wang R, Janson C, Smith W, Krysa G, Boullay V, De Gouville AC, Huet S and Hartley D: Identification of 1,5-naphthyridine derivatives as a novel series of potent and selective TGF-beta type I receptor inhibitors. J Med Chem 47: 4494-4506, 2004

19. Callahan JF, Burgess JL, Fornwald JA, Gaster LM, Harling JD, Harrington FP, Heer J, Kwon C, Lehr R, Mathur A, Olson BA, Weinstock $J$ and Laping NJ: Identification of novel inhibitors of the transforming growth factor beta1 (TGF-beta1) type 1 receptor (ALK5). J Med Chem 45: 999-1001, 2002

20. Takemura S, Yashiro M, Sunami T, Tendo M and Hirakawa K: Novel models for human scirrhous gastric carcinoma in vivo. Cancer Sci 95: 893-900, 2004.

21. Mizumoto N, Gao J, Matsushima H, Ogawa Y, Tanaka H and Takashima A: Discovery of novel immunostimulants by dendriticcell-based functional screening. Blood 106: 3082-3089, 2005.

22. Tanaka H, Matsushima H, Nishibu A, Clausen BE and Takashima A: Dual therapeutic efficacy of vinblastine as a unique chemotherapeutic agent capable of inducing dendritic cell maturation. Cancer Res 69: 6987-6994, 2009.

23. Sato M, Takayama T, Tanaka H, Konishi J, Suzuki T, Kaiga T and Tahara $\mathrm{H}$ : Generation of mature dendritic cells fully capable of T helper type 1 polarization using OK-432 combined with prostaglandin E(2). Cancer Sci 94: 1091-1098, 2003.

24. Suzuki E, Kim S, Cheung HK, Corbley MJ, Zhang X, Sun L, Shan F, Singh J, Lee WC, Albelda SM and Ling LE: A novel small-molecule inhibitor of transforming growth factor beta type I receptor kinase (SM16) inhibits murine mesothelioma tumor growth in vivo and prevents tumor recurrence after surgical resection. Cancer Res 67: 2351-2359, 2007.
25. Uhl M, Aulwurm S, Wischhusen J, Weiler M, Ma JY, Almirez R, Mangadu R, Liu YW, Platten M, Herrlinger U, Murphy A, Wong DH, Wick W, Higgins LS and Weller M: SD-208, a novel transforming growth factor beta receptor I kinase inhibitor, inhibits growth and invasiveness and enhances immunogenicity of murine and human glioma cells in vitro and in vivo. Cancer Res 64: 7954-7961, 2004

26. Criswell TL, Dumont N, Barnett JV and Arteaga CL: Knockdown of the transforming growth factor-beta type III receptor impairs motility and invasion of metastatic cancer cells. Cancer Res 68: 7304-7312, 2008.

27. Bandyopadhyay A, Lopez-Casillas F, Malik SN, Montiel JL Mendoza V, Yang J and Sun LZ: Antitumor activity of a recombinant soluble betaglycan in human breast cancer xenograft. Cancer Res 62: 4690-4695, 2002.

28. Kobie JJ, Wu RS, Kurt RA, Lou S, Adelman MK, Whitesell LJ, Ramanathapuram LV, Arteaga CL and Akporiaye ET: Transforming growth factor beta inhibits the antigen-presenting functions and antitumor activity of dendritic cell vaccines. Cancer Res 63: 1860-1864, 2003.

29. Ito M, Minamiya Y, Kawai H, Saito S, Saito H, Nakagawa T, Imai K, Hirokawa $M$ and Ogawa J: Tumor-derived TGFbeta- 1 induces dendritic cell apoptosis in the sentinel lymph node. J Immunol 176: 5637-5643, 2006.

30. Matsuyama S, Iwadate M, Kondo M, Saitoh M, Hanyu A, Shimizu K, Aburatani H, Mishima HK, Imamura T, Miyazono K and Miyazawa K: SB-431542 and Gleevec inhibit transforming growth factor-beta-induced proliferation of human osteosarcoma cells. Cancer Res 63: 7791-7798, 2003

31. Inman GJ, Nicolas FJ, Callahan JF, Harling JD, Gaster LM, Reith AD, Laping NJ and Hill CS: SB-431542 is a potent and specific inhibitor of transforming growth factor-beta superfamily type I activin receptor-like kinase (ALK) receptors ALK4, ALK5, and ALK7. Mol Pharmacol 62: 65-74, 2002.

32. Banchereau J, Briere F, Caux C, Davoust J, Lebecque S, Liu YJ, Pulendran B and Palucka K: Immunobiology of dendritic cells. Annu Rev Immunol 18: 767-811, 2000

33. Morelli AE, Zahorchak AF, Larregina AT, Colvin BL, Logar AJ, Takayama T, Falo LD and Thomson AW: Cytokine production by mouse myeloid dendritic cells in relation to differentiation and terminal maturation induced by lipopolysaccharide or CD40 ligation. Blood 98: 1512-1523, 2001.

34. Lyakh LA, Sanford M, Chekol S, Young HA and Roberts AB: TGF-beta and vitamin D3 utilize distinct pathways to suppress IL-12 production and modulate rapid differentiation of human monocytes into CD83 ${ }^{+}$dendritic cells. J Immunol 174: 2061-2070, 2005.

35. Grauer O, Poschl P, Lohmeier A, Adema GJ and Bogdahn U: Toll-like receptor triggered dendritic cell maturation and IL-12 secretion are necessary to overcome T-cell inhibition by gliomaassociated TGF-beta2. J Neurooncol 82: 151-161, 2007.

36. Larmonier N, Marron M, Zeng Y, Cantrell J, Romanoski A, Sepassi M, Thompson S, Chen X, Andreansky S and Katsanis E: Tumor-derived CD4(+)CD25(+) regulatory $\mathrm{T}$ cell suppression of dendritic cell function involves TGF-beta and IL-10. Cancer Immunol Immunother 56: 48-59, 2007.

37. West MA, Wallin RP, Matthews SP, Svensson HG, Zaru R, Ljunggren HG, Prescott AR and Watts C: Enhanced dendritic cell antigen capture via toll-like receptor-induced actin remodeling. Science 305: 1153-1157, 2004.

38. Fernandez NC, Lozier A, Flament C, Ricciardi-Castagnoli P, Bellet D, Suter M, Perricaudet M, Tursz T, Maraskovsky E and Zitvogel L: Dendritic cells directly trigger NK cell functions: cross-talk relevant in innate anti-tumor immune responses in vivo. Nat Med 5: 405-411, 1999.

39. Kim S, Buchlis G, Fridlender ZG, Sun J, Kapoor V, Cheng G, Haas A, Cheung HK, Zhang X, Corbley M, Kaiser LR, Ling L and Albelda SM: Systemic blockade of transforming growth factor-beta signaling augments the efficacy of immunogene therapy. Cancer Res 68: 10247-10256, 2008.

40. Valenti R, Huber V, Filipazzi P, Pilla L, Sovena G, Villa A, Corbelli A, Fais S, Parmiani G and Rivoltini L: Human tumorreleased microvesicles promote the differentiation of myeloid cells with transforming growth factor-beta-mediated suppressive activity on T lymphocytes. Cancer Res 66: 9290-9298, 2006. 